\title{
Favre-racouchot syndrome: Case report
}

\author{
Ujjawal Kumar', Krishnendra Varma ${ }^{2}$, Harsh Vardhan Shesha ${ }^{3, *}$ \\ ${ }^{1}$ Associate Professor, ${ }^{2}$ Professor and Head, ${ }^{3}{ }^{\text {rd }}$ Year Postgraduate Student, Dept. of Dermatology, R.D. Gardi Medical College, \\ Ujjain, Madhya Pradesh, India
}

*Corresponding Author:

Email: singingshesha05@gmail.com

\begin{abstract}
It is also known as nodular elastosis with cyst and comedones. The pathophysiology of disease causation is unknown, the condition may arises due to prolonged sun exposure. We report a case of 68 year old male agriculturist who presented with dark colored raised lesions along with thickening of facial skin which was increasing progressively since past three years. Physical examination showed the presence of thickened inelastic skin along with deep furrows and wrinkles involving the entire face, along with multiple open and closed comedones yellowish papules and nodules clustered especially around periocular region and dorsum of nose. On histopathological examination epidermis showed epidermal cyst formation containing laminated keratin and superficial dermis shows follicular infundibular plugging and large nodules filled with keratinous material.
\end{abstract}

Keywords: Prolonged sun exposure, Bilateral, Nodular elastoidosis with cyst and comedones.

\section{Introduction}

Favre-Racouchot Syndrome (FRS) also known as Nodular elastoidosis with cysts and comedones occurring as consequences of solar degeneration of the skin, clinically characterized by the presence of multiple comedones, cysts, furrows and diffuse yellowish nodules predominantly clustered around periorbital region of an elderly. ${ }^{1}$ The disorder is not an uncommon condition, and it occurs in up to $6 \%$ of people older than 50 years of age. The incidence increases with advancing age, the exact pathophysiology is not known. It is presumed that disorder develops in individuals with prolonged sun exposure and history of heavy smoking. ${ }^{2}$

\section{Case Report}

We report a case of 68 year old elderly male, agriculturist by occupation who presented with history of slowly expanding dark colored lesions on his cheeks along with gradual coarseness of facial features. There was no history of pain/itching over lesions. Physical examination showed the presence of thickened inelastic skin along with deep furrows and wrinkles involving whole face, particularly prominent on forehead, zygomatic and malar areas of face. Also multiple large open and closed comedones yellowish papules and nodules clustered especially around periocular region and dorsum of nose. The comedones had central opening with dark plug. The Lesions are usually bilaterally symmetrical. He also had deep furrowing of skin at the nape of the neck, with intersecting skin folds resulting in rhomboidal configurations which gives appearance of 'cutis rhomboidalis nuche'. The patient was farmer by occupation with an average working of 8 hours daily. He never followed sun protective measures or used any sunscreens. There were no history of drug intake or associated systemic illness, no history of exposure to chemicals or toxins or application of any cosmetics or medical creams to the face. He had been smoking more than 20 cigarettes a day for the past 4 decades. The patient was emotionally disturbed with the ugly appearance of his face. On histological examination, epidermis shows epidermal cyst formation containing laminated keratin and superficial dermis shows follicular infundibular plugging with large nodules filled with keratinous material. Overall features correlates with the findings of Favre Racouchot syndrome and final diagnosis was made.

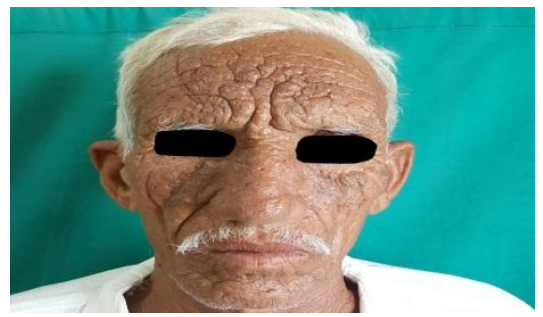

Fig. 1: Shows The skin of forehead, zygomatic and malar areas of face is atrophic, inelastic and showed deep wrinkles with multiple comedones, yellowish colored papules and nodules over cheeks and forehead

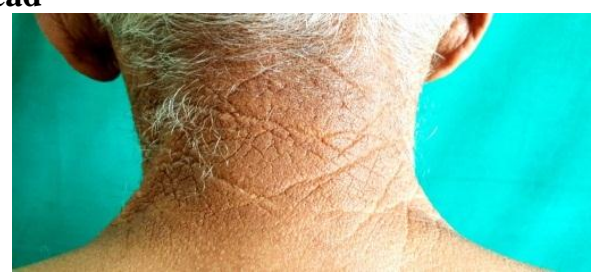

Fig. 2: Shows deep furrowing of the skin at the nape of the neck, with intersecting skin folds resulting in rhomboidal configurations which gives appearance of 'cutis rhomboidalis nuche' 


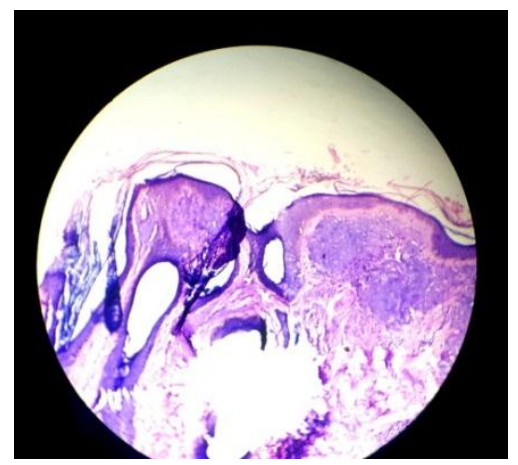

Fig. 3: $H \& E$ (100x) section shows covering of stratified squamous epithelium and underlying fibrocollagenous stroma. Epidermis shows epidermal cyst formation containing loosely arranged laminated keratin. The superficial dermis shows follicular infundibular plugging and large nodules filled with keratinous material.

\section{Discussion}

Discoveries in medical sciences and improved social science during past few decades medical care have prolonged the lifespan of elderly population. Favre-Racouchot syndrome is a peculiar dermatosis characterized by the presence of nodular cutaneous elastosis with cysts and comedones on photo damaged skin, which predominantly affects the face and less commonly neck. The condition was first described in 1932 by the French dermatologist Maurice Favre, ${ }^{4}$ which was further reviewed in detail by Favre and his student Jean Racouchot in $1951^{5}$ and henceforth termed Favre-Racouchot syndrome. Individuals with white skin are predisposed more than pigmented skin. It is estimated that the condition occurs in $1.4 \%$ of the adult population and in $6 \%$ of white men older than 50 years. ${ }^{6}$ Middle-aged to elderly individuals are more commonly affected, but fewer number of cases have been reported during second decade of life. The number of males cases outnumbered the females cases, probably because of excessive sun-exposure and effect of smoking.

It is a peculiar syndrome clinically, characterized by diffuse yellowish hue with multiple large comedones on actinically damaged skin. ${ }^{3}$ Comedones may be closed (whiteheads) or open (blackheads). Lesions are symmetrical in distribution more pronounced on the forehead, periorbital and temporal region and sometimes over the neck, deep wrinkles and furrows on actinically damaged and atrophic skin. The exact pathophysiology of disease causation remains unclear. It is presumed that prolonged sun exposure and individuals with history of heavy cigarette smoking are the predisposing factors for disease. UV light damages the elastic network of the mid and upper dermis with subsequent reduction of its tensile strength. Various other conditions associated with FRS are cutis rhomboidalis nuchae, trichostasis spinulosa, actinic keratosis, keratoacanthoma, basal cell carcinoma, and squamous cell carcinoma. ${ }^{6}$ The confirmation of diagnosis is made primarily through clinical and rarely required histopathology. On the basis of typical facial appearance and location of the lesions (comedones, cysts, and nodules on solar-damaged skin). However, the histologic features of FRS are very characteristic with presence of epidermal cyst formation containing laminated keratin and superficial dermis shows follicular infundibular plugging with large nodules. The condition has cosmetic concern and socially embarrassing. The prognosis is good if the patient is treated properly. ${ }^{3}$

Several measures which can reduce the disease progression include avoidance of sun-exposure, especially during peak hours of UV radiation intensity, regular use of broad spectrum sunscreens, cessation of smoking is strictly advised, wearing of sun protective hats and clothes before going to the outdoor is adviced. Topical retinoids such as tretinoin, adapalene, tazarotene are the mainstay of medical treatment. ${ }^{3}$ This medication works by repairing collagen and remodeling elastin in the dermis. ${ }^{7}$ In addition, the medication may decrease the activity of MMP within the skin and decreases collagen breakdown. Regular use of these medications results in expulsion of small comedones and improvement in photodamaged skin. Daily use of oral Isotretinoin $(0.05-0.1 \mathrm{mg} / \mathrm{kg} /$ day $)$ in combination with topical tretinoin have been found to be effective. ${ }^{6}$ Surgical procedures include comedone extraction, curettage, dermabrasion, and laser resurfacing gives good results in such cases.

\section{References}

1. Pelachyk JM: Nodular elastoidosis with cysts and comedones, in: Clinical Dermatology, Editor, Demis DJ: Harper and Row, Philadelphia, 1987; Vol 1, Unit 4-44:p $1-3$.

2. Keough GC, Laws RA, Elston DM. Favre-Racouchot syndrome: a case for smokers' comedones. Arch Dermatol. 1997 Jun. 133(6):796-7.

3. Sonthalia S, Arora R, Chhabra N, Khopkar U. FavreRacouchot syndrome. Indian Dermatol Online J. 2014;5 (suppl 2):S128-S129.

4. Favre M. Sur une affection kystique des appareils pilosébacés localisée à certaines régions de la face. Bull Soc Fr Dermatol Syphiligr. 1932;39:93-96.

5. Favre M, Racouchot J. L'élastoïdose cutanée nodulaire à kystes et à comédons. Ann Dermatol Syphiligr (Paris). 1951;78(6):681-702.

6. Patterson WM, Fox MD, Schwartz RA. Favre-Racouchot disease. Int J Dermatol. 2004;43(3):167-169.

7. Sutherland AE, Green PJ. Favre-Racouchot syndrome in a 39-year old female following radiation therapy. J Cutan Med Surg. 2014;18(1):72-74. 